\title{
Erratum to: Neutron capture measurements and resonance parameters of dysprosium
}

S.G. Shin ${ }^{1}$, Y.U. Kye ${ }^{1}$, W. Namkung ${ }^{1}$, M.H. Cho ${ }^{1}$, Y.-R. Kang ${ }^{2}$,a, M.W. Lee ${ }^{2}$, G.N. Kim ${ }^{3, b}$, T.-I. Ro $^{4}$, Y. Danon $^{5}$, D. Williams ${ }^{5}$, G. Leinweber ${ }^{6}$, R.C. Block ${ }^{6}$, D.P. Barry ${ }^{6}$, and M.J. Rapp ${ }^{6}$

1 Division of Advanced Nuclear Engineering, Pohang University of Science and Technology, Pohang, Gyeongbuk 37673, Republic of Korea

2 Research Center, Dongnam Inst. of Radiological \& Medical Sciences, Busan 46033, Republic of Korea

3 Department of Physics, Kyungpook National University, Daegu 41566, Republic of Korea

4 Dong-A University, Department of Physics, Busan 49315, Republic of Korea

${ }^{5}$ Department of Mechanical, Aerospace, and Nuclear Engineering, Rensselaer Polytechnic Institute, Troy, NY 12180-3590, USA

6 Naval Nuclear Laboratory, Knolls Atomic Power Laboratory, P.O. Box 1072, Schenectady, NY 12301, USA

Original article: Eur. Phys. J. A (2017) 53: 203, https://doi.org/10.1140/epja/i2017-12402-7

Received: 9 November 2017

Published online: 6 December 2017 - C Società Italiana di Fisica / Springer-Verlag 2017

After publication of the paper, the authors realized that the acknowledgements were not correct. Their correct version appears below.

This research was partly supported by the Institutional Activity Program of KAERI, 2017 and by the National R\&D Program through the Dong-nam Institute of Radiological \& Medical Sciences (50496-2017).

\footnotetext{
a e-mail: yeongrok@dirams.re.kr

b e-mail: gnkim@knu.ac.kr
} 